\title{
Individual Laboratory-Measured Discount Rates Predict Field Behavior
}

\section{Citation}

Chabris, Christopher F., David Laibson, Carrie L. Morris, Jonathon P. Schuldt, and Dmitry Taubinsky. 2008. Individual laboratory-measured discount rates predict field behavior. Journal of Risk and Uncertainty 37, no. 2-3: 237-269.

\section{Published Version}

doi:10.1007/s11166-008-9053-x

\section{Permanent link}

http://nrs.harvard.edu/urn-3:HUL.InstRepos:11130522

\section{Terms of Use}

This article was downloaded from Harvard University's DASH repository, and is made available under the terms and conditions applicable to Open Access Policy Articles, as set forth at http:// nrs.harvard.edu/urn-3:HUL.InstRepos:dash.current.terms-of-use\#OAP

\section{Share Your Story}

The Harvard community has made this article openly available.

Please share how this access benefits you. Submit a story.

Accessibility 
NBER WORKING PAPER SERIES

INDIVIDUAL LABORATORY-MEASURED DISCOUNT RATES PREDICT FIELD BEHAVIOR

Christopher F. Chabris

David Laibson

Carrie L. Morris

Jonathon P. Schuldt

Dmitry Taubinsky

Working Paper 14270

http://www.nber.org/papers/w14270

\author{
NATIONAL BUREAU OF ECONOMIC RESEARCH \\ 1050 Massachusetts Avenue \\ Cambridge, MA 02138 \\ August 2008
}

The authors wish to thank Kirill Babikov, Ananya Chakravarti, Lee Chung, Alison H. Delargy, Margaret E. Gerbasi, J. Richard Hackman, Jill M. Hooley, Steven E. Hyman, Thomas Jerde, Stephen M. Kosslyn, Melissa A. Liebert, Sarah Murphy, Jacob Sattelmair, Aerfen Whittle, and Anita W. Woolley for their advice, assistance, and support of this research. We acknowledge financial support by a NARSAD Young Investigator Award and DCI Postdoctoral Fellowship awarded to Christopher F. Chabris, an NSF ROLE grant to J. Richard Hackman and Stephen M. Kosslyn, and NIA (P01 AG005842, R01 AG021650) and NSF (0527516) grants to David I. Laibson The views expressed herein are those of the author(s) and do not necessarily reflect the views of the National Bureau of Economic Research.

(C) 2008 by Christopher F. Chabris, David Laibson, Carrie L. Morris, Jonathon P. Schuldt, and Dmitry Taubinsky. All rights reserved. Short sections of text, not to exceed two paragraphs, may be quoted without explicit permission provided that full credit, including ()$_{\text {notice, }}$ is given to the source. 
Individual Laboratory-Measured Discount Rates Predict Field Behavior

Christopher F. Chabris, David Laibson, Carrie L. Morris, Jonathon P. Schuldt, and Dmitry

Taubinsky

NBER Working Paper No. 14270

August 2008

JEL No. C91,D9,I1

\begin{abstract}
We estimate discount rates of 555 subjects using a laboratory task and find that these individual discount rates predict inter-individual variation in field behaviors (e.g., exercise, BMI, smoking). The correlation between the discount rate and each field behavior is small: none exceeds 0.28 and many are near 0 . However, the discount rate has at least as much predictive power as any variable in our dataset (e.g., sex, age, education). The correlation between the discount rate and field behavior rises when field behaviors are aggregated: these correlations range from 0.09-0.38. We present a model that explains why specific intertemporal choice behaviors are only weakly correlated with discount rates, even though discount rates robustly predict aggregates of intertemporal decisions.
\end{abstract}

Christopher F. Chabris

Department of Psychology

Union College

807 Union Street

Schenectady, NY 12308

chabrisc@union.edu

David Laibson

Department of Economics

Littauer M-12

Harvard University

Cambridge, MA 02138

and NBER

dlaibson@harvard.edu

Carrie L. Morris

Washington University School of Medicine

Campus Box 8505

4444 Forest Park Avenue

Campus Box

St. Louis, MO 63108

clmorris@post.harvard.edu
Jonathon P. Schuldt

Department of Psychology

University of Michigan

3232 East Hall

530 Church St.

Ann Arbor, MI 48109

jschuldt@umich.edu

Dmitry Taubinsky

Harvard University

Kirkland House

Cambridge, MA 02138

taubinsk@fas.harvard.edu 


\section{Introduction}

Social, risk, and time preferences are the three principal types of preference variation in economic models. In this paper we provide a general analysis of the importance of time preferences in predicting individual differences in behavior. We measure time preferences by asking subjects to make 27 binary choices between an immediate monetary reward and a delayed monetary reward of larger size (using potentially real rewards and a computerized implementation of a questionnaire devised by Kirby et al., 1999). We use these choices to estimate an intertemporal discount function for each subject. We then calculate the correlation between subjects' discount rates and subjects' field behaviors. We focus on behaviors that involve an intertemporal tradeoff and therefore should be associated with intertemporal preferences. These include various measures of smoking, drinking, exercise, nutrition, saving, borrowing, wealth, and gambling.

We find that the discounting glass is half full. On the one hand, field behaviors and discount rates are only weakly correlated - no correlation is greater than 0.28 and many correlations are close to zero. By this metric, discount rates do not appear to have a large degree of predictive power a correlation coefficient of 0.10 implies an $R^{2}$ of only $1 \%$.

However, such low $R^{2}$ statistics are only the beginning of the story. We find that each of several other individual-level variables, such as sex, age, depression symptoms, education, and cognitive ability, typically has less predictive power than our measure of time discounting. ${ }^{1}$ In many of the statistical horse races that we conduct among these potential predictors, the discount rate is the runaway winner. Moreover, the relative success of the discount rate rises even further when we aggregate the field behaviors into an index. The correlation between the estimated discount rate and the sum of the normed field behaviors ranges from 0.09 to 0.38 (implying $R^{2}$ values that range from roughly $1 \%$ to $15 \%$ ). We conclude that the discount rate, even when measured with a brief laboratory task, is one of the most important variables that we have to explain individual differences.

\footnotetext{
${ }^{1}$ Such small influences of specific personality traits is consistent with findings in both the psychological and economic literatures on individual differences, even for well-measured traits such as intelligence (e.g., Ross \& Nisbett, 1991; Richard et al., 2003; Swann \& Selye, 2005; Chabris et al., 1998; Barsky et al., 1997; see also Cutler \& Glaeser, 2005).
} 
We present a model that unifies these findings. Our model assumes that behavior derives from three sources: traits that predict behavioral impatience (e.g., the discount rate), traits that predict other broad classes of behavior (e.g., the coefficient of relative risk aversion), and idiosyncratic factors (e.g., residence in a state with low cigarette taxes). Using this framework, we explain why it is unlikely that any single trait would have substantial predictive power for any particular behavior. However, the framework predicts that an aggregated index of behavior should be relatively highly correlated with particular traits. For example, an index of behaviors that involve intertemporal tradeoffs should in principle be highly correlated with a laboratory measure of a discount rate. Our empirical results confirm this property.

This paper contributes to the literature on intertemporal choice in several ways. We base our analysis on three new databases that have not been previously studied. To our knowledge, our empirical analysis has one of the largest sample sizes (555) of any study of time preferences and field behaviors yet published. ${ }^{2}$ Our data have two other desirable features. First, our subject pool, though composed of convenience samples, is reasonably diverse on all demographic characteristics except geography. Second, we measure 15 field behaviors. Almost all previous studies have focused on a single field behavior, including those in which subjects were selected for substance abuse or impulse-control disorders (reviewed by Reynolds, 2006; Chabris et al., 2008). We do not engage in empirical cherry-picking. We report results for every field behavior in our dataset that was hypothesized to reflect impatience or impulsivity - warts and all. This provides a balanced view of the successes and the failures of the time preference paradigm. Finally, we argue that it is important to compare predictive power across explanatory variables (instead of relying on the absolute level of an $R^{2}$ statistic) and that it is important to study indices of behaviors rather than individual behaviors. When judged this way, discount rates turn out to be a key variable in explaining individual differences in choices involving intertemporal tradeoffs.

The paper is divided into four sections. Following this introduction, in section II we describe our three new databases. In section III we summarize our econometric methods and report our empirical results. In section IV we present our theoretical framework. In section V we conclude by

\footnotetext{
${ }^{2}$ Other studies with similar-size samples (e.g., de Wit et al., 2007) have been concerned with correlating discount rates with personality traits, intelligence, and other individual difference measures, rather than with field behaviors.
} 
discussing the limitations of this study and directions for future research.

\section{Data description}

Dozens of studies have demonstrated a relationship between laboratory measures of discounting and various behaviors and traits, including smoking (e.g., Bickel et al., 1999; Mitchell, 1999), gambling (e.g., Dixon et al., 2003), cognitive ability (e.g., Benjamin et al., 2006; for a review see Shamosh \& Gray, 2008), heroin use (e.g., Kirby et al., 1999), age (e.g., Green et al., 1994), alcoholism (e.g., Petry, 2001), and brain injury (e.g., Dixon et al., 2005). ${ }^{3}$ In general, this literature shows that higher rates of discounting are associated with problematic and impulsive behaviors, drug use being one particularly well-studied domain (e.g., Reynolds, 2006). Many discounting studies target a clinical population (alcoholics, pathological gamblers) and infer discount rates from a series of choices between a smaller, more immediate reward (usually real or hypothetical money) and a larger, delayed reward, which are then compared to the discount rates of control subjects who do not have the diagnosis in question. To our knowledge, no previous paper has used a wide range of behaviors to estimate and compare the predictive strength of the discount rate and the predictive strength of other demographic variables. The present study utilizes data from three independent, relatively large, diverse samples, which feature numerous traits and field behaviors.

\subsection{Three Datasets}

Intertemporal choice data were collected as part of three independent studies. For all three samples, we used the 27-choice delay-discounting task created by Kirby et al. (1999), and in all studies we administered the task by computer. Choice trials were presented to subjects in a fixed order. On each trial, subjects indicated their preference for either a smaller, immediate reward (SIR) or a larger, delayed reward (LDR). The trial order and specific reward amounts and delays are shown

\footnotetext{
${ }^{3}$ There is also a nascent literature that relates different field measures of discounting. For example, Cutler and Glaeser (2005) argue that such relationships are weak because field behaviors that have intertemporal consequences have low intra-individual correlations. Scharff and Viscusi (2008) report evidence of field behaviors that have strong relationships at the group level. Our model (Section 4) reconciles these perspectives.
} 
in Table 1. Table 2 shows summary descriptive statistics for the samples we use in our analysis. Each of the three samples is described below.

\subsection{Weight Study}

\subsubsection{Subjects}

One hundred and forty-six individuals participated in the study. ${ }^{4}$ All subjects were recruited from the greater Boston area via advertisements appearing in a free community newspaper and postings in various public spaces. Because the study was primarily concerned with the relationship between body mass index (BMI) and measures of impulsivity, separate advertising targeted normal-weight, overweight, and obese subjects, offering $\$ 20$ and a chance at earning additional money in return for one hour of participation in the laboratory and willingness to fast for 12 hours prior to the session. All subjects were high school graduates, English speakers, and reported having no family history of serious mental illness. BMIs of the subjects ranged from 18.7 to $60.5(\mathrm{M}=29.0, \mathrm{SD}=7.1)$.

Current U.S. government standards specify that a BMI of 18-25 is labeled "normal weight," a BMI between 25 and 30 is labeled "overweight," and a BMI 30 or greater is labeled "obese."

We exclude subjects who always chose either the delayed or the immediate reward $(\mathrm{N}=5)$, because for those subjects we cannot estimate a discount rate based on the data.

In addition, we do not include subjects whose discount rates were estimated to be in the top $5 \%(\mathrm{~N}=7)$ of the empirical distribution of the estimated discount rates. We exclude the top $5 \%$ because our data are extremely right-skewed (before the exclusion): the minimum discount rate is $4.08 \times 10^{-6}$, the 5 th percentile is $3.48 \times 10^{-4}$, the 10 th percentile is 0.001 , the 50 th percentile is 0.007 , the 90 th percentile is 0.044 , the 95 th percentile is 0.102 , and the maximum is 0.241 . As a consequence of this skewed distributional pattern, regressions are dominated by a few outliers in the right tail of the data. To explore the robustness of our results, we have redone all of our analysis using the percentile of the discount rate (instead of the raw discount rate) without excluding the top

\footnotetext{
${ }^{4}$ Eighteen additional subjects were tested but were immediately excluded from data analysis for one or more of the following reasons: reported brain injury; reported mental illness; reported drug use; had difficulty understanding directions; was unable to complete the protocol; was previously tested.
} 
5\%. This nonlinear transformation of the discount rate data prevents the right tail observations from dominating the analysis and none of the qualitative results of this study change.

Finally, we exclude subjects who have missing data in any of the variables we study $(\mathrm{N}=8)$. The three types of exclusions leave us with a final sample for the Weight Study of 126 subjects.

\subsubsection{Measures}

Delay-discounting. The Kirby et al. (1999) 27-item delay-discounting task was administered using Psyscope 1.2.5 software (Cohen et al., 1993) on Apple Macintosh computers running OS 9. To make the task incentive compatible, each participant had a 1-in-6 chance of receiving an additional $\$ 11$ to $\$ 85$ monetary reward (in addition to the promised $\$ 20$ show-up fee), reflecting their indicated preference on one randomly selected trial. At the end of the laboratory session, the participant rolled a six-sided die; if a 6 was rolled, the participant blindly selected one card from a box containing cards numbered 1-27 to determine the trial that would be paid off. If, on that trial, an immediate reward was selected, the amount was added to the $\$ 20$ and a check request for the total was submitted on the same day (or the next business day) to the research administration office. If a delayed reward was selected, a $\$ 20$ check request was made immediately, and a second request for the reward amount was submitted after the specified number of days had elapsed. Checks were mailed to subjects approximately two weeks after requests were submitted.

Demographic variables. Subjects reported their age (in years), sex (male or female), and highest level of education (which was used to estimate a total number of years of education; e.g., high school $=12$ years, college degree $=16$ years, law school $=19$ years, etc.).

Health-related variables. Subjects reported on a variety of health-related behaviors, including smoking, dieting status, and physical exercise (see Appendix 2a for exact item wording). BMI was used to assess each participant's body weight adjusted for height. Heights and weights were measured in the laboratory using measuring tape and a Taylor 300 portable scale. Each participant's BMI was calculated using the standard formula: weight $(\mathrm{kg}) /[\text { height }(\mathrm{m})]^{2}$.

In addition, the Beck Depression Inventory-II was used to measure depression symptoms. The BDI-II (Beck et al., 1996) is a 21-item self-report questionnaire that assesses the presence and 
severity of depression symptoms during the previous two weeks. Questions correspond to the criteria for major depressive disorder outlined in the fourth edition of the Diagnostic and Statistical Manual of Mental Disorders. Each question is multiple-choice and each response is scored on a 4-point (03) scale. Responses are summed into a total score that ranges from 0 to 63 , with higher scores suggesting more severe depression: A total score between 0 and 13 indicates minimal depression, 14-19 indicates mild depression, 20-28 indicates moderate depression, and 29-63 indicates severe depression. ${ }^{5}$

\subsubsection{Procedure}

Subjects were tested individually in private rooms around mid-day. ${ }^{6}$ After giving informed consent, each participant completed the BDI-II and then was measured for height and weight (in each case with shoes removed).

Each participant was next administered a questionnaire that contained some of the healthrelated measures and the demographic measures mentioned above, as well as additional questions not analyzed here. Subjects then completed the delay-discounting task. The task's instructions were closely adapted from Kirby et al. (1999) and explained that each participant would be asked to choose between receiving a SIR or a LDR on 27 choice trials. The instructions emphasized that subjects should take the task seriously, because at the end of the study, there would be a 1-in- 6 chance that one of their choices would be randomly chosen and implemented. Each participant verbally summarized the instructions to the investigator and any misunderstandings were corrected before the task began.

Subjects then completed a task that involved making decisions about pictures of food (not reported here), and a second questionnaire that included the remaining health measures, including dieting and alcohol consumption. At the end of the session, subjects followed the procedure mentioned above to determine what (if any) additional payment they would receive based on their

\footnotetext{
${ }^{5}$ The BDI-II has high internal consistency among college students (0.93) and clinical populations (0.92) and adequate validity (Beck et al., 1996).

${ }^{6}$ Each subject brought a lunch, and was randomly assigned to eat that lunch either before or after completing the study ( $50 \%$ chance of being assiged to each condition). This variable was not considered in any of the analyses reported in this paper.
} 
discounting task choices.

\subsection{Cognition study}

The Cognition study examined individual differences in various cognitive and decision making abilities. Some results from this study are reported elsewhere (e.g., Chabris, 2007).

\subsubsection{Subjects}

One hundred and thirty-six individuals participated in this study. ${ }^{7}$ All subjects were recruited from the greater Boston area via advertisements appearing in a free community newspaper, postings in various public spaces, and lists of volunteers for studies in the Harvard University psychology department. They were offered $\$ 50$, as well as a 1 -in- 6 chance of winning up to $\$ 85$ more, for their participation. Approximately two thirds were university students and one third were local community residents. All subjects reported no use of drugs or psychoactive medications, no history of psychiatric or neurological illness, fluency in English, and having completed high school.

We exclude subjects who always chose either the delayed or the immediate reward $(\mathrm{N}=3)$, because for those subjects we cannot estimate a discount rate based on the data.

As in the Weight Study, we do not include subjects whose discount rates were estimated to be in the top $5 \%(\mathrm{~N}=6)$ of the empirical distribution of the estimated discount rates. We exclude the top $5 \%$ because our data are extremely right-skewed (before the exclusion): the minimum discount rate is $2.87 \times 10^{-4}$, the 5 th percentile is $7.83 \times 10^{-4}$, the 10 th percentile is 0.001 , the 50 th percentile is 0.006 , the 90 th percentile is 0.036 , the 95 th percentile is 0.084 , and the maximum is 0.281 . As a consequence of this skewed distributional pattern, regressions are dominated by a few outliers in the right tail of the data. To explore the robustness of our results, we have redone all of our analysis using the percentile of the discount rate (instead of the raw discount rate) without excluding the top 5\%. This nonlinear transformation of the discount rate data prevents the right tail observations

\footnotetext{
${ }^{7}$ Sixteen additional subjects were tested but were immediately excluded from data analysis for one or more of the following reasons: reporting brain injury, mental illness, or drug use; having difficulty understanding or following directions; not meeting eligibility criteria (such as not being a native English speaker); failing to complete the entire testing session; having data missing for one or more of the cognitive tasks (usually due to equipment failure or experimenter error).
} 
from dominating the analysis and none of the qualitative results of this study change.

Finally, we exclude subjects who were missing data in any of the variables we study $(\mathrm{N}=24)$. The three types of exclusions leave us with a final sample for the Cognition Study of 103 subjects.

\subsubsection{Measures}

Delay-discounting. The task and procedure were the same as in the Weight study.

Demographics. A self-report questionnaire was used to measure age, sex, height and weight (from which BMI was calculated as in the Weight Study), and highest level of education completed (which was converted into years of education as in the Weight Study).

Cognitive ability composite. Subjects completed a series of eight tests described in Appendix 1a.

\subsubsection{Procedure}

Subjects were tested individually in private rooms. After giving informed consent, each participant completed the self-report demographic questionnaire, followed by a series of computerized and paper-and-pencil tasks that took approximately 3.5 hours. Included in this series were the delaydiscounting task (which was administered as in the Weight Study) and the cognition measures mentioned above, as well as several other personality and decision-making tests not reported here. At the end of the session, subjects followed the procedure used in the Weight Study to determine what (if any) additional payment they would receive based on their discounting task choices. All payments were made by check following the procedure described for the Weight Study.

\subsection{Web study}

The Web study examined individual differences in various cognitive abilities in relation to personal background characteristics (especially educational and occupational specialization) and behaviors. No laboratory visits were involved; subjects completed all components of this study via the Internet. Other results from these data are reported elsewhere (e.g., Chabris et al., 2007; Liebert et al., 2007). 


\subsubsection{Subjects}

Four hundred and twenty-two individuals participated in the study. ${ }^{8}$ Subjects were recruited through advertisements posted on community web sites (e.g., Craigslist) and direct emails to special membership lists (e.g., science graduate students). Because these data were collected as a part of a study primarily concerned with investigating differences in cognitive ability among individuals with different types of post-secondary training and occupations, recruitment materials specified that prospective subjects should hold a college degree (however, approximately $8 \%$ of the total sample reported having fewer than than four years of post-secondary education). Advertisements offered a $\$ 10$ gift certificate to Amazon.com and, similar to the Weight and Cognition studies, a 1-in-6 chance of winning an additional gift certificate worth up to $\$ 85$ in exchange for completing a series of cognitive tasks and questionnaires online lasting approximately 45 minutes. All subjects reported being English speakers and U.S. citizens or residents.

Of the 422 original subjects we do not include subjects who had three or more responses below $200 \mathrm{~ms}$ on the discounting task $(\mathrm{N}=5)$, because such rapid responses may indicate rote responding. ${ }^{9}$ We exclude subjects who always chose either the delayed or immediate reward $(\mathrm{N}=8)$, because for those subjects we cannot estimate a discount rate based on their data.

As in the Weight and Cognition Studies, we do not include subjects whose discount rates were estimated to be in the top $5 \%(\mathrm{~N}=19)$ of the empirical distribution of the estimated discount rates. We exclude the top $5 \%$ because our data are extremely right-skewed (before the exclusion): the minimum discount rate is $2.39 \times 10^{-6}$, the 5 th percentile is $4.83 \times 10^{-4}$, the 10 th percentile is $8.63 \times 10^{-4}$, the 50 th percentile is 0.006 , the 90 th percentile is 0.025 , the 95 th percentile is 0.041 , and the maximum is 0.230 . As a consequence of this skewed distributional pattern, regressions are dominated by a few outliers in the right tail of the data. To explore the robustness of our results, we have redone all of our analysis using the percentile of the discount rate (instead of the raw discount rate) without excluding the top $5 \%$.

This nonlinear transformation of the discount rate data prevents the right tail observations from

\footnotetext{
${ }^{8}$ The Web study used a different screening questionnaire than the Weight and Cognition Studies. The Web screen did not ask about several of the exclusion criteria (e.g., mental illness) that were used in those studies.

${ }^{9}$ This criterion was also applied to the other two datasets, but no subjects in those studies were excluded.
} 
dominating the analysis and none of the qualitative results of this study change.

Finally, we exclude subjects who have any missing data in the variables that we study $(\mathrm{N}=64)$. The three types of exclusions leave us with a final sample for of 326 subjects for the Web Study.

\subsubsection{Measures}

Cognitive ability composite. Subjects completed a series of 10 tests to measure individual differences in cognitive ability, nine of which were based on the "MRAB" (Minicog Rapid Assessment Battery) developed by Shephard and Kosslyn (2005) (see Appendix 1b for a complete listing of the cognitive tests). Performance on each test was measured as the percentage of trials answered correctly, except for Verbal Fluency, which was scored as the total number of different words generated in three one-minute trials.

Delay-discounting. Kirby and colleagues' (1999) delay-discounting task was administered using Psyscope-FL, a tool for Macintosh OS X that compiles PsyScope experiments into Flash movies that run on the participant's personal computer and transmit the response data back to a server. As in the Weight and Cognition studies, subjects were given a 1-in-6 chance of receiving their preferred reward on one randomly selected trial to encourage truthful revelation of preferences.

Health-related variables. Subjects self-reported a variety of personal heath-related behaviors, including smoking, physical exercise, healthy food choices, dental health (frequency of dentist visits, flossing frequency), and prescription drug compliance (see Appendix 2b for exact item wording).

Finance-related variables. Subjects self-reported a variety of personal finance-related behaviors, including percentage of income saved, gambling, late credit card payments, and wealth accumulation relative to friends and siblings (see Appendix 2c for exact item wording).

\subsubsection{Procedure}

Individuals who responded to advertisements were sent an e-mail message containing a link to the Web-based battery of cognitive tests and questionnaires. After providing informed consent, subjects completed the 10 cognitive tests in order, followed by a series of questionnaires that included the delay-discounting task and a "lifestyle questionnaire" containing the health- and finance-related 
questions. All subjects received their $\$ 10$ gift certificate to Amazon.com by email soon after completing the study, and approximately one-sixth of subjects were emailed an additional gift certificate in an amount determined by their choice on one (randomly selected) delay-discounting trial, after the specified delay. These rewards were normally emailed on the same or next business day that they were due to be paid.

\section{Results}

\subsection{Estimation of Discount Functions}

We use a generalized hyperbola to model time preferences. Specifically, we assume that for each subject $i$, the discounted value of a one unit reward in $\tau$ days is

$$
D(\tau)=\frac{1}{1+\alpha_{i} \tau}
$$

A plot of $D(\tau)$ is given in Figure 1. Previous studies linking discount rates to behavior have adopted this function as well (e.g., Mazur, 1987; Kirby \& Marakovic, 1996; Kirby et al., 1999; de Wit et al., 2007; Myerson \& Green, 1995; Rachlin et al., 1991). ${ }^{10}$

This discount function $D(\tau)$ is a special case in the family of hyperbolic discount functions derived by Loewenstein and Prelec (1992):

$$
D(\tau)=(1+\alpha \tau)^{-\gamma / \alpha}
$$

In this family of discount functions, the discount rate - the rate of decline of the discount functionis given by

$$
\frac{-\frac{\partial D(\tau)}{\partial \tau}}{D(\tau)}=\frac{\gamma}{1+\alpha \tau} .
$$

Hence, the discount rate is decreasing with delay time $\tau$. The declining discount rate generates

\footnotetext{
${ }^{10}$ We do not use multi-parameter discount functions (e.g., Laibson, 1997), because we want to study a discount function with only one free parameter; thereby simplifying the comparison between a person's unique "discount rate" and their field behavior.
} 


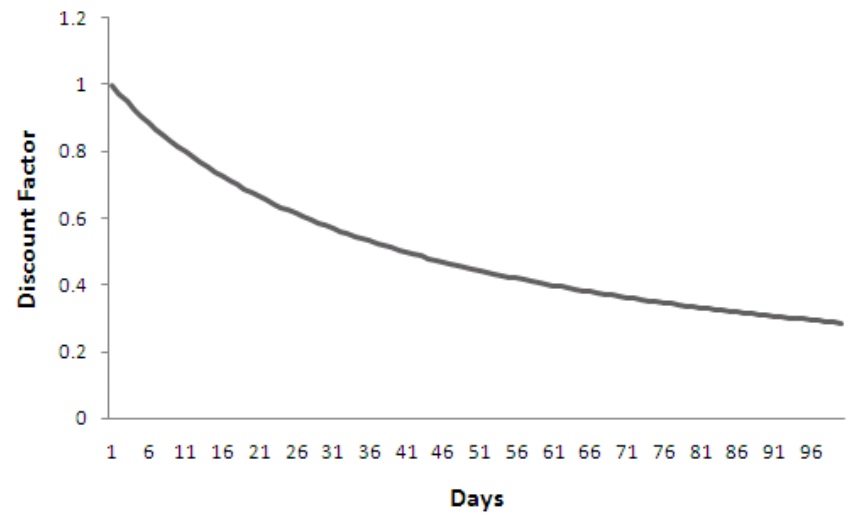

Figure 1: Plot of $D(\tau)$ when $\alpha=.05$

dynamically inconsistent time preferences (Strotz, 1957; Ainslie, 1992).

Our specification imposes the common restriction $\gamma=\alpha$. Hence, the discount rate at horizon $\tau$ is given by

$$
\frac{-\frac{\partial D(\tau)}{\partial \tau}}{D(\tau)}=\frac{\alpha}{1+\alpha \tau}
$$

At horizon $\tau=0$, the discount rate is $\alpha$. To simplify notation, we refer to parameter $\alpha$ as the "discount rate," though it is actually only the instantaneous discount rate at horizon $\tau=0$.

Taken literally, these time preferences imply that a subject $i$ chooses $Y$ in $\tau$ days over an immediate reward of $X$ if and only if the net present value of $Y$ exceeds $X$ :

$$
\frac{Y}{1+\alpha_{i} \tau}-X \geq 0
$$

We assume that subjects' preferences experience shocks distributed according to the logistic distribution with mean 0 and unit variance ${ }^{11}$ so that subject $i$ chooses the delayed reward with probability

$$
F_{\text {Logit }}\left(\frac{Y}{1+\alpha_{i} \tau}-X\right)=\frac{e^{\frac{Y}{1+\alpha_{i} \tau}}}{e^{X}+e^{\frac{Y}{1+\alpha_{i} \tau}}} .
$$

\footnotetext{
${ }^{11}$ We fix the variance to 1 so that our likelihood function is maximized at a unique value. Over half of the subjects in our dataset had consistent responses that could be rationalized by any $\alpha \in\left[\alpha_{m}, \alpha_{M}\right]$, for some $\alpha_{m}<\alpha_{M} \in \mathbb{R}$. For these subjects, the model would not be identified with a free variance parameter.
} 
Estimates of each subject's discounting parameter, $\hat{\alpha}_{i}$, are obtained by maximizing the likelihood function

$$
\mathcal{L}_{i}\left(\alpha, d_{i}\right)=\prod_{t=1}^{27}\left[F_{\text {Logit }}\left(\frac{Y_{t}}{1+\alpha \tau_{t}}-X_{t}\right)\right]^{d_{i t}}\left[1-F_{\text {Logit }}\left(\frac{Y_{t}}{1+\alpha \tau_{t}}-X_{t}\right)\right]^{1-d_{i t}}
$$

where $d_{i}=\left(d_{i 1}, \ldots, d_{i 27}\right)$ is the vector of the 27 binary decisions of subject $i$. In trial $t$, dummy variable $d_{i t}=1$ if subject $i$ chose the delayed reward $Y_{t}$ in $\tau_{t}$ days over the immediate reward $X_{t}$ (otherwise $d_{i t}=0$ ).

In our final, post-exclusion datasets, the mean estimated discounting parameter $\hat{\alpha}_{i}$ is 0.015 (sd 0.020) for the Weight sample, 0.009 (sd 0.009) for the Cognition sample, and 0.008 (sd 0.009) for the Web sample.

\section{$3.2 \quad$ Weight study}

The Weight study asks respondents about four health-related variables that are associated with intertemporal tradeoffs and thus should be partially predicted by the discount function. These variables are body mass index (BMI), exercise frequency, whether subjects were on a diet or not (binary measure), and number of packs of cigarettes typically consumed per week.

Exercise frequency is normalized to 0 for subjects who do not exercise. Similarly, the packs of cigarettes variable is normalized to 0 for subjects who do not smoke. (For these two variables we run both OLS and tobit regressions.) These normalizations are used in all three studies: Weight, Cognition, and Web.

Before running our statistical tests, we multiplicatively transform the behavioral variables so that in all cases, a greater (transformed) behavioral value is hypothesized to correlate with a higher discount rate. Specifically, exercise frequency is negatively transformed because (untransformed) exercise is an investment activity and should therefore correlate negatively with the discount rate. The negative transformation of exercise should therefore correlate positively with the discount rate. Diet status is likewise negatively transformed - being on a diet is also an investment activity. These normalizations are used in all three studies: Weight, Cognition, and Web. 
The explanatory variables we use are the estimated discount rates, age, age squared, sex, years of education, and BDI. Table 3 shows regression results. We run both OLS and tobit regressions for exercise frequency, and cigarette consumption. For the binary diet variable we use both a linear probability model and a probit model. For the nonlinear models, we compute a pseudo- $R^{2}$ statistic called Efron's $R^{2}$, equal to the square of the correlation between the predicted probabilities or values and the actual values. ${ }^{12}$

The effects of time preferences are statistically significant at $p<0.01$ for exercise frequency and BMI and statistically significant at $p<0.05$ for cigarette consumption. ${ }^{13}$ For the diet variable, discounting is not significant. ${ }^{14}$ Overall, discounting and the other explanatory variables account for about $14.5 \%-19.0 \%$ of the variance in BMI, smoking, and exercise. The $R^{2}$ for dieting behavior is less than $5 \%$.

We also find that, on average, the discount rate explains the most variation in each of the individual variables we study. Table 4 reports the $R^{2}$ values. The first 4 rows of the table correspond to the four health variables we study and the 5th row is an average of the first 4 rows, reporting the average variance explained by the independent variables. The first column reports $R^{2}$ values for OLS regressions when the health variables are regressed on all of the explanatory variables. The subsequent columns report $R^{2}$ values when the health behaviors are regressed on only one of the explanatory variables. Because all regressions are OLS regressions, the entries in columns 2-7, with the exception of column 4 , are simply the squares of the correlation between the health variables and the explanatory variables. ${ }^{15}$

As Table 4 shows, no variables, including a square function of age, explain as much variance as discounting. The table also shows that while some variables are good at explaining a particular behavior (for example, BDI explains a large portion of the variance of consumption of cigarettes),

\footnotetext{
${ }^{12}$ For a probit model, for example, Efron's $R^{2}$ is simply $R^{2}=1-\frac{\sum_{i=1}^{N}\left(y_{i}-\hat{\pi}_{i}\right)^{2}}{\sum_{i=1}^{n}\left(y_{i}-\bar{y}\right)^{2}}$, where $y_{i}$ are the observed values, $\bar{y}$ is their average, and $\hat{\pi}_{i}$ is the predicted probability.

${ }^{13}$ Scharff and Viscusi (2008) analyze data on workers' wage-fatality risk tradeoffs and find that smokers' discount rates are almost twice as big as those of non-smokers.

${ }^{14}$ While dieting is generally considered a health investment, one potential problem with this variable is that a person is more likely to go on a diet if he/she is overweight, which could be due to a high degree of impatience.

${ }^{15}$ We use OLS regressions because the $R^{2}$ 's of the OLS regressions have a simple interpretation as the square of the correlation and fraction of variance explained. It is not clear what the probit or tobit counterpart should be. However, as Table 3 suggests, nonlinear regression models do not change the results significantly.
} 
discounting is the only variable that consistently explains at least $2 \%$ of the variance in each of the four health behaviors.

We also create two indices for aggregate investment in health activities. Index 1 is the sum of the four health investment variables we study in this dataset (each separately standardized to have mean 0 and unit variance). Index 2 is the first principal component of these four standardized variables. ${ }^{16}$ Table 5 shows the coefficient vector of each component. The first principal component accounts for $35.5 \%$ of the common variance. The first principal component is constructed with positive weights on each of the four health variables in Table 5, implying that this component represents a mechanism that is generally associated with health investment (like patience). The other components do not have weights with a common sign, suggesting that these components do not account for domain-general variation in health investments.

Table 6 and Table 7 report regressions of the two indices on each on the explanatory variables. The first columns of both tables report the coefficients, standard errors, and $R^{2}$ values from OLS regressions when all explanatory variables are used in the regression. The second columns report these statistics when only the discounting variable is used as an independent variable, the third columns report statistics when only the age and age-squared variables are used, and so forth. Overall, Table 6 and Table 7 look similar. The explanatory variables account for about $25 \%$ of the variance of each index. On its own, the discount rate accounts for approximately $14 \%$ of the variance. Specifically, Table 6 shows that the discount rate explains $14.6 \%$ of the variance and Table 7 shows that the discount rate explains $14.1 \%$ of the variance. No other variable explains such a large fraction of the variance. The depression measure, BDI, comes in second place, explaining $8.8 \%$ and $10.0 \%$ of the variance of indices 1 and 2 , respectively.

\subsection{Cognition study}

The cognition study has data on two health behaviors - BMI and exercise frequency. The explanatory variables we use are the subjects' estimated discount rates, age, age squared, sex, years of

\footnotetext{
${ }^{16}$ Thus the coefficient vectors of the components are extracted as eigenvectors of the correlation (rather than covariance) matrix of the non-standardized variables.
} 
education, and a composite score for general cognitive ability. This composite is computed by extracting the first principal component from eight tests designed to measure different cognitive abilities. The principal components analysis is done using standardized variables, so that the coefficient vectors of the principal components are the eigenvectors of the correlation matrix of the test scores. The first principal component accounts for $35 \%$ of the variance of the eight mental ability tests (a typical proportion; Chabris, 2007).

Table 8 shows the regressions relating our explanatory variables to the two health behaviors in this dataset: BMI and exercise frequency. The discounting variable is associated significantly with BMI $(p<0.05)$ but it is not associated significantly with exercise frequency $(p>0.10)$. The cognitive ability composite is also highly significant in the BMI regression $(p<0.01)$.

Table 9 shows that on average, the estimated discount rates explain the most variance. The cognitive ability index comes in a close second ( $0.4 \%$ difference), and explains far more variation than any of the remaining variables. Previous studies (e.g., Burks et al. 2008; Benjamin et al., 2006) have shown that cognitive skills are associated significantly with preferences in choice domains such as risk-taking and saving, so it is no surprise that our cognitive ability index explains a relatively large portion of the variance in BMI and exercise frequency. That the estimated discount rates have more predictive power is especially impressive when one considers that the discount rate has the disadvantage that it is inferred from a brief 27 -question task, whereas our cognitive ability index is extracted from eight different multi-trial tests, representing a total of 682 questions.

In addition, discounting is the only variable that explains any of the variation of the sum of the standardized BMI and exercise variables (analogous to index 1 in the Weight study). Table 10 shows that discounting is significant at $p<0.01$ and explains $6.9 \%$ of the variance. Each of the other variables explain less than $1 \%$ of the variance, and combined they explain only an additional $3 \%$ of the variance.

\subsection{Web study}

The Web study has data for eight relevant health behaviors-BMI, cigarette consumption, exercise frequency, dental check-ups, overeating, flossing, selection of healthy food, and following doctors' 
prescriptions. In addition, this data set measures six financial behaviors-gambling, paying late fees on a credit card, paying a credit card bill in full, savings, and wealth. ${ }^{17}$

The explanatory variables we use are the same as the ones in the Cognition study. The cognitive ability index is again extracted as the first principal component from a set of cognitive tests, but the ten cognitive tests in the Web study differ from the eight cognitive tests in the Cognition study. The first principal component now explains $39 \%$ of the common variance.

Table 11 shows OLS regression results for the eight health behaviors. In the BMI regression, all variables, including discounting but excluding education, are highly significant $(p<0.01)$ and explain $15.6 \%$ of the variance. The exercise regression has an $R^{2}$ of $9.6 \%$ and the six other regressions have an $R^{2}$ less than $5.5 \%$. The effect of discounting is positive and significant only in the BMI regression. Unexpectedly, the coefficient on the discount rate has a negative point estimate in four out of the eight regressions - exercise, dental check-ups, flossing, and following doctors' prescriptions - and the negative estimate is significant in the prescriptions regression.

Table 12 shows OLS regression results for the six financial behaviors. The regressions for gambling and paying the credit card bill in full have an $R^{2}$ of about $11.5 \%$, and $9.1 \%$, respectively. The four other regressions have an $R^{2}$ below $4 \%$. Discounting has a highly significant effect in the credit card bill regression $(p<0.01)$ but is insignificant in all other regressions. In the wealth relative to siblings regression, the effect of discounting has a negative (though insignificant) point estimate.

The Web study is a relatively noisy dataset, obscuring the effects of discounting as well as the effects of other variables. This may be partly due to the fact that the Web study was not conducted in a controlled lab environment. Table 13, which reports $R^{2}$ values from OLS regressions, indicates that no variable explains a substantial amount of variance in the behaviors we measure. The first column of the table lists the behaviors, and the top row lists the right-hand-side variables. As shown in the bottom row of the table, all the variables combined explain only about $5.5 \%$ of the variance, on average. In the Weight and Cognition studies, the corresponding numbers are 13.5\% and $11.0 \%$.

Table 13 shows that discounting explains very little variance in the behaviors we measure, even

\footnotetext{
${ }^{17}$ Wealth is measured in relative terms: "compared to friends" and "compared to other members of your family in your generation."
} 
when compared to the other explanatory variables like sex. The bottom row of Table 13 shows that the cognitive ability index explains the most variance. This may occur for two reasons. First, cognitive ability does interact significantly with preferences (e.g., Burks et al., 2008). Second, the cognitive ability index was extracted from ten different multi-trial tests (441 questions in total) and is thus a relatively reliable measure. Age and sex are also probably measured precisely because of the straightforward nature of those variables.

Nevertheless, Table 15 and Table 16 show that discounting has a significant effect when used to predict an index of behaviors that involve intertemporal tradeoffs ( $p<0.10$ and $p<0.05$ for indices 1 and 2 , respectively). We create the first index by standardizing the 14 behaviors we study in this dataset and taking their sum. The second index is the first principal component extracted from the 14 (standardized) behaviors. Table 14 shows the coefficients of the first principal component. The OLS regressions in these tables show that a quadratic function of age explains the most variance, with discounting and the cognitive ability index explaining approximately the same amount of variance, and with sex, education, and a linear function of age explaining very little. The amount of variance in these indices that is explained by discounting is much smaller than the corresponding amounts in the Weight and Cognition studies.

\section{Theoretical Framework}

\subsection{Model}

Consider a set of $n$ behaviors that are each associated with an intertemporal tradeoff (e.g., cigarette smoking). Let $B_{1}, \ldots, B_{n}$ be the levels of behavior in these $n$ domains. Norm these behaviors, so a higher level $B_{i}$ of behavior $i$ is associated with a greater reward now and a lower reward in the future. For example, one can overeat now at the cost of poorer health and appearance later; smoke a pack of cigarettes now at the cost of reduced cardiovascular health later; or go on a shopping spree now at the cost of having to cut expenditure later. To keep our analysis simple, we assume that all behaviors are continuous choices over some convex subset of $\mathbb{R}$. 
The reduced form equations for these behaviors are

$$
B_{i}=a_{i} X^{\prime}+b_{i} Y^{\prime}+\sum_{j=1}^{t_{i}} \eta_{i j}
$$

where $a_{i}=\left(a_{i 1}, \ldots, a_{i r}\right)$ and $b_{i}=\left(b_{i 1}, \ldots, b_{i s}\right)$ are scalar vectors respectively in $\mathbb{R}^{r}$ and $\mathbb{R}^{s}$, and $X=\left(X_{1}, \ldots, X_{r}\right), Y=\left(Y_{1}, \ldots, Y_{s}\right)$, and $\eta_{i}=\left(\eta_{i 1}, \ldots, \eta_{i t_{i}}\right)$ are random vectors respectively in $\mathbb{R}^{r}$, $\mathbb{R}^{s}$, and $\mathbb{R}^{t_{i}}$. All random variables $-\left\{X_{i}\right\},\left\{Y_{i}\right\}$, and $\left\{\eta_{i j}\right\}$ - are mutually independent, and the variables $\left\{X_{i}\right\}$ and $\left\{Y_{i}\right\}$ are normalized to have unit variance.

Assume that the random variables $X_{1}, \ldots, X_{r}$ correspond to domain-general traits that are normalized so that they are positively correlated with all the elements of the behavior vector, with $X_{1}$ representing the discount rate. The random variables $Y_{1}, \ldots, Y_{s}$ are the domain-general traits that are positively correlated with some behaviors $B_{i}$ but negatively correlated with others. Finally, the random variables $\eta_{i j}$ correspond to behavior-specific idiosyncratic tastes. An extended discussion of $\eta_{i j}$ is presented in the next subsection. ${ }^{18}$

\subsection{Motivating micro-foundation}

Our reduced-form framework is motivated by the following two-period model. In period 1, agents choose a level $B_{i}$ of activity in each domain $i$. The benefit they receive from this level of activity is $u\left(B_{i}\right)$, where $u$ is concave, differentiable, and increasing. In period 2, agents incur a linear discounted cost of $\frac{1}{1+\alpha} a_{i 1} B_{i} \simeq(1-\alpha) a_{i 1} B_{i}$ for engaging in this activity in period 1 .

Let $Z=\left(X_{2}, \ldots, X_{r}, Y_{1}, \ldots, Y_{s}\right)$ be the vector of all domain-general traits other than the discount rate $\alpha$, and let $c_{i}=\left(a_{i 2}, \ldots, a_{i r}, b_{i 1}, \ldots, b_{i s}\right)$ represent the vector of coefficients corresponding to $Z$. Define $\gamma_{i} \equiv \sum_{j=1}^{t_{i}} \eta_{i j}$ and assume that

$$
u\left(B_{i}\right)=\left(c_{i} Z^{\prime}+\gamma_{i}\right) B_{i}-\frac{B_{i}^{2}}{2},
$$

\footnotetext{
${ }^{18}$ Cutler and Glaeser (2005) present a different but related framework. They make the identifying assumption that each of the domain general traits predicts all (relevant) behaviors with a uniform sign. Our evidence is inconsistent with their assumption. In the Weight study, for example, being female is associated positively with exercising less $(\mathrm{r}=0.10)$ but associated negatively with smoking $(\mathrm{r}=-0.18)$. Because of these considerations, the Cutler-Glaeser approach of using the correlation of two behaviors to derive an upper bound for the correlation between a behavior and a domain general trait (e.g. discounting) is not justified. Therefore, we do not use their framework.
} 
Hence, an agent's traits have a linear effect on her benefit from $B_{i}$. We think of this parametric set-up as a first-order approximation to the true function.

If an agent discounts the future with approximate factor $(1-\alpha)$ and maximizes her total utility, she must choose $B_{i}$ to maximize

$$
\left(c_{i} Z^{\prime}+\eta_{i}\right) B_{i}-\frac{B_{i}^{2}}{2}-(1-\alpha) a_{i 1} B_{i}
$$

This implies the relationship,

$$
B_{i}=a_{i 1}(\alpha-1)+c_{i} Z^{\prime}+\gamma_{i}
$$

which is an alternative representation of equation (1).

\subsection{How much variance should discounting explain?}

Consider again equation (1). Apart from discounting, other domain-general traits that may affect the level of activity in domain $i$ are age, sex, years of education, cognitive abilities, or depression. In addition to those, there are the domain-specific random variables, $\eta_{i j}$. Taking smoking as an example, here are some illustrations of $\eta_{i j}$ mechanisms:

- Living in a state with a low tax rate on cigarettes

- Family attitude toward smoking when growing up

- Having a partner who smokes or who hates smoking

- Having an older friend or sibling who could provide cigarettes at a young age

- Living near a store that (illegally) sells cigarettes to minors

- Wanting to use smoking as an instrument for weight loss

- Exposure to cigarette advertising (or anti-smoking advertising)

- Seeing celebrities smoke 
All of these variables should be expected to have some effect on smoking behavior. Even the seemingly superficial ones, such as seeing a favorite movie star smoke, have been shown to have a significant statistical effect (Distefan et al., 1999, 2004). In addition to this list, there are myriad other variables that affect a person's demand for cigarettes, including genetic variables that influence how one responds biologically to the taste of a cigarette or to the neural effects of nicotine.

Letting $i=1$ be the smoking domain, the fraction of the variance of smoking behavior $\left(B_{1}\right)$ accounted for by discounting is

$$
\frac{a_{11}^{2}}{\sum_{i=1}^{r} a_{1 i}^{2}+\sum_{i=1}^{s} b_{1 i}^{2}+\sum_{i=1}^{t_{1}} \sigma_{1 i}^{2}}
$$

where $\sigma_{i j}^{2}=\operatorname{Var}\left(\eta_{i j}\right)$. As a simple numerical illustration, assume that there are 100 terms in the denominator, coming from both domain-general variables and domain-specific variables. If the discounting variable was measured perfectly and accounted for $N$ times the variance accounted for by each of the other 99 variables, then discounting would still account for only $N \%$ of the total variance. By comparison, in the Weight study, our (noisy) estimates of subjects' discounting parameters accounted for $5.9 \%$ of the variance in smoking behavior.

Even if discounting is by far the best predictor of the behaviors that we study, we should still not expect discounting to explain a large fraction of the variance in these behaviors since the behaviors are affected by many different variables.

\subsection{Discounting and aggregate investment}

Predicting isolated intertemporal decisions is less important than predicting total health investment. For example, Grossman's (1972) model of health investment-Cutler and Glaeser (2005) call this "the prevailing economic paradigm" — is not a model of specific behaviors such as dieting, smoking, or exercising. Rather, it is a model of consumers' total investment in "health stock." We argue that discounting is a robust predictor of aggregate investment.

In the framework that we have developed here, discounting is predicted to be a much better determinant of the aggregate of all intertemporal choices than it is of any particular intertemporal 
choice. Let $B=\sum_{i=1}^{n} B_{i}$ be the total of all intertemporal behaviors. Then the fraction of the variance of $B$ accounted for by discounting is

$$
\rho \equiv \frac{\left(\sum_{i=1}^{n} a_{i 1}\right)^{2}}{\sum_{j=1}^{r}\left(\sum_{i=1}^{n} a_{i j}\right)^{2}+\sum_{j=1}^{s}\left(\sum_{i=1}^{n} b_{i j}\right)^{2}+\sum_{i=1}^{n} \sum_{j=1}^{t_{i}} \sigma_{i j}^{2}}
$$

Set $\bar{a}_{j} \equiv \frac{1}{n} \sum_{i=1}^{n} a_{i j}$ and $\bar{b}_{j} \equiv \frac{1}{n} \sum_{i=1}^{n} b_{i j}$, so that $\bar{a}_{j}$ and $\bar{b}_{j}$ are the average effects of a domaingeneral variable $X_{j}$ or $Y_{j}$ on behavior. Then equation (2) can be rewritten as

$$
\rho=\frac{\bar{a}_{1}^{2}}{\sum_{j=1}^{r} \bar{a}_{j}^{2}+\sum_{j=1}^{s} \bar{b}_{j}^{2}+\frac{1}{n^{2}} \sum_{i=1}^{n} \sum_{j=1}^{t_{i}} \sigma_{i j}^{2}} .
$$

Note that

$$
\lim _{n \rightarrow \infty} \frac{1}{n^{2}} \sum_{i=1}^{n} \sum_{j=1}^{t_{i}} \sigma_{i j}^{2}=0
$$

as long as all variances are uniformly bounded. Thus for large $n$,

$$
\rho \approx \frac{\bar{a}_{1}^{2}}{\sum_{j=1}^{r} \bar{a}_{j}^{2}+\sum_{j=1}^{s} \bar{b}_{j}^{2}} .
$$

In other words, when the number of behaviors, $n$, is large, the fraction of the variance of the aggregate of the behaviors that is explained by domain-specific idiosyncratic effects will be small, and actually converges to 0 as $n \rightarrow \infty$. Thus the fraction of the variance that is explained by discounting will (generally) rise with $n$, converging to the share of variance that discounting explains relative to what is explained by all domain-general variables.

Additionally, if we make the natural assumption that $\bar{b}_{j} \approx 0$ for all $j$, then

$$
\rho \approx \frac{\bar{a}_{1}^{2}}{\sum_{j=1}^{r} \bar{a}_{j}^{2}}
$$

In words, if the domain-general variables that move the $B_{i}$ in different directions have an average effect of approximately zero on aggregate behavior when we take enough different behaviors into account, then the fraction of variance of aggregate behavior explained by discounting is simply the 
share of variance that discounting explains relative to what is explained by all the domain-general variables that move all the intertemporal behaviors in the same direction. In our Weight study, for example, we find that when we aggregate just four health related behaviors, discounting explains $14.6 \%$ of the variance. When we regress just the standardized smoking variable on discounting the $R^{2}$ is $5.9 \%$, but this statistic goes up by about $1 \%-4 \%$ with each additional behavior that we include in the aggregated index. Thus we expect that discounting would explain an even larger fraction of the variance of aggregate behavior if we measured more than four types of investment behavior. It would probably also rise if we measured the discount rate more precisely.

Our empirical analysis is actually somewhat different from the one in the theoretical framework. Because we do not know what the comparable units are for each of the behaviors $B_{i}$, we first norm the behaviors by dividing them by their standard deviation, $S_{i}$, and then aggregate them to get $B$. Thus instead of working with approximations for $a_{i j}, b_{i j}$ and $\sigma_{i j}$ we work with approximations for $a_{i j}^{\dagger}=a_{i j} / S_{i}, b_{i j}^{\dagger}=b_{i j} / S_{i}$, and $\left(\sigma_{i j}^{\dagger}\right)^{2}=\sigma_{i j}^{2} / S_{i}^{2}$, respectively, and the quantity we estimate is the fraction of variance of the aggregate of standardized behaviors that is accounted for by discounting. Now as long as the $S_{i}$ are bounded away from 0 , it is still true that the $\sigma_{i j}^{2} / S_{i}^{2}$ will be bounded and thus

$$
\lim _{n \rightarrow \infty} \frac{1}{n^{2}} \sum_{i=1}^{n} \sum_{j=1}^{t_{i}}\left(\sigma_{i j}^{\dagger}\right)^{2}=0 .
$$

In summary, the quantity we estimate is

$$
\rho^{\dagger}=\frac{\bar{a}_{1}^{2}}{\sum_{j=1}^{r} \bar{a}_{j}^{2}+\sum_{j=1}^{s} \bar{b}_{j}^{2}+\frac{1}{n^{2}} \sum_{i=1}^{n} \sum_{j=1}^{t_{i}}\left(\sigma_{i j}^{\dagger}\right)^{2}}
$$

where $\bar{a}_{j} \equiv \frac{1}{n} \sum_{i=1}^{n} a_{i j}^{\dagger}$, and $\bar{b}_{j} \equiv \frac{1}{n} \sum_{i=1}^{n} b_{i j}^{\dagger}$. For large enough $n, \rho^{\dagger}$ is approximately the share of the variance of the aggregate of standardized behaviors that discounting accounts for, relative to the share of the variance that is accounted for by all domain-general traits.

$$
\rho^{\dagger} \approx \frac{\bar{a}_{1}^{2}}{\sum_{j=1}^{r} \bar{a}_{j}^{2}+\sum_{j=1}^{s} \bar{b}_{j}^{2}}
$$




\section{Conclusion}

Our analysis leads us to two conclusions with seemingly opposite messages. First, we show that discount rates are only weakly correlated with field behaviors (e.g., smoking, drinking, and BMI). In our analysis, no correlation is greater than 0.28 and many correlations are close to zero. Viewed through this statistical lens, discount rates do not have a large degree of predictive power.

However, there is an alternative viewpoint. We find that the other individual-level variables in our datasets - sex, age, education, cognitive ability, and depression symptoms - typically have even less predictive power than the discount rate, despite their almost certainly being measured with less error than the discount rate. Moreover, the relative superiority of the discount rate over other predictors is enhanced when we aggregate field behaviors into an index. The correlation between the estimated discount rate and the index of field behaviors ranges from 0.09 to 0.38 . We conclude that the discount rate is, in fact, the most important variable that we have to explain individual differences in behaviors that generate intertemporal tradeoffs.

These results are not paradoxical. Behavioral outcomes are influenced by hundreds of variables and a near-infinity of circumstances, happenstances, and coincidences. We should therefore not be surprised to find that a single variable like the discount rate only has a modest absolute level of predictive power. It is also not surprising that the discount rate proves superior to other demographic variables. These other variables are themselves only single contributors to behaviors that derive from many sources. Finally, one should expect the discount rate to play an increasingly important predictive role as we intensify the behavioral signal by forming an index of different behaviors that all have intertemporal consequences.

Our analysis has several shortcomings that should be addressed by future research. First, our survey method, including the battery of 27 intertemporal choice questions from Kirby et al. (1999), is probably generating a noisy measure of the discount rate, which is biasing down the predictive power of this measure. Future work should try to improve the measurement of the discount rate. Different (potentially longer) batteries of questions and different discount functions should be explored. Second, some of the behaviors that we study may be miscoded. Is exercise 
an investment in future appearance and health (our coding) or is exercise an activity that offers immediate gratification (e.g., the "runner's high" that releases endogenous opioids in the brain; Boecker et al., 2008)? The coding of dieting is also questionable. Is dieting a sign of patience (our coding) or a covariate of impatience? Being overweight is a frequent precursor of going on a diet. Third, our sample is diverse but it is not representative of the U.S. population. ${ }^{19}$ Our subjects are geographically concentrated in Boston and relatively more educated than the U.S. population. Fourth, one of our three surveys (Web) has very noisy observations. It is not clear what to make of the results from this part of our analysis. With these caveats in mind, we consider our results to be only suggestive. However, we believe that these methodological problems have primarily reduced the statistical clarity of our findings rather than biasing our results towards the conclusions that we have reported.

Finally, our results support two broad conclusions: (1) there exists a domain-general behavioral disposition towards impatience/impulsivity, and (2) a discount rate estimated through a set of intertemporal monetary choice questions constitutes a useful, though noisy, measure of this disposition. This method of measuring an individual's impatience has advantages over traditional personality tests, which simply ask participants to introspectively evaluate and explicitly state their own dispositions rather than to demonstrate them and implicitly disclose them through a sequence of decisions with (potentially) real consequences. In addition to improving the measurement of this trait, future research can use discount rates as phenotypes in genetic studies designed to identify the molecular mechanisms of intertemporal choice.

\footnotetext{
${ }^{19}$ Note that because our studies used convenience samples rather than population samples, all of our variables likely have lower variance than they do in the larger population. However, this observations applies to both sides of our regressions and therefore may not bias our estimates. It is critical that more representative samples be studied in the future.
} 


\section{References}

Ainslie, G. 1992. Picoeconomics. New York: Cambridge University Press.

Barsky, B., Juster, F.T., Kimball, M. \& Shapiro, M., (1997). Preference Parameters and Behavioral Heterogeneity: An Experimental Approach in the Health and Retirement Study. The Quarterly Journal of Economics, 112(2), 537-579.

Beck, A.T., Steer, R.A., \& Brown, G.K. (1996). Manual for the Beck Depression Inventory, 2nd ed. San Antonio, TX: The Psychological Corporation.

Benjamin, D.J., Brown, S.A., \& Shapiro, J.M. (2006). Who is 'Behavioral'? Cognitive ability and anomalous preferences. Harvard University mimeo, May.

Bickel, W.K., Odum A.L., \& Madden, G.J. (1999). Impulsivity and cigarette smoking: delay discounting in current, never, and ex-smokers. Psychopharmacology, 146, 447-454.

Boecker, H., Sprenger, T., Spilker, M.E., Henriksen, G., Koppenhoefer, M., Wagner, K.J., et al. (2008). The Runner's High: Opioidergic Mechanisms in the Human Brain. Cerebral Cortex, doi:10.1093/cercor/bhn013.

Bors, D.A., \& Stokes, T.L. (1998). Raven's Advanced Progressive Matrices: Norms for first-year university students and the development of a short form. Educational and Psychological Measurement, 58, 382-398.

Burks, S.V., Carpenter, J.P., Götte, L., \& Rustichini, A. (July 2008). Cognitive Skills Explain Economic Preferences, Strategic Behavior, and Job Attachment. Institute for the Study of Labor Discussion Paper No. 3609.

Bush, G., Shin, L.M., Holmes, J., Rosen, B.R., \& Vogt, B.A. (2003). The Multi-Source Interference Task: Validation study with fMRI in individual subjects. Molecular Psychiatry, 8, 60-70.

Chabris, C.F. (2007). Cognitive and neurobiological mechanisms of the Law of General Intelligence. In M.J. Roberts (Ed.), Integrating the mind: Domain specific versus domain general processes in higher cognition (pp. 449-491). Hove, UK: Psychology Press. 
Chabris, C.F., et al. (1998). Does IQ matter? Commentary, 106(5), 13-23.

Chabris, C.F., Gerbasi, M.E., Liebert, M.A., Nakayama, K., \& Duchaine, B.C. (2007). Face recognition as a special cognitive ability: An individual differences study. Presented at the Annual Meeting of the Cognitive Neuroscience Society, New York, 5-8 May.

Chabris, C.F., Laibson, D.I., \& Schuldt, J.P. (2008). Intertemporal choice. In S.N. Durlauf \& L.E. Blume (Eds.), The New Palgrave Dictionary of Economics (2nd ed.). London: Palgrave Macmillan.

Cohen, J.D., MacWhinney, B., Flatt, M., \& Provost, M. (1993). PsyScope: A new graphic interactive environment for designing psychology experiments. Behavioral Research Methods, Instruments, and Computers, 25, 257-271.

Cutler, D.M., \& Glaeser, E.L. (February 2005). What Explains Differences in Smoking, Drinking and Other Health-Related Behaviors? Harvard Institute of Economic Research Discussion Paper No. 2060.

de Wit, H., Flory, J.D., Acheson, A., McCloskey, M., \& Manuck, S.B. (2007). IQ and nonplanning impulsivity are independently associated with delay discounting in middle-aged adults. Personality and Individual Differences, 42(1), 111-121.

Distefan, J.M., Gilpin, E.A., Sargent, J.D., \& Pierce, J.P. (1999). Do movie stars encourage adolescents to start smoking? Evidence from California. Preventive Medicine, 28, 1-11.

Distefan, J.M., Pierce J.P., \& Gilpin, E.A. (2004). Do favorite movie stars influence adolescent smoking initiation? American Journal of Public Health, 94(7), 1239-1244.

Dixon, M.R., Jacobs, E.A., Sanders, S., Guercio, J.M., Soldner, J., Parker-Singler, S., et al. (2005). Impulsivity, self-control, and delay discounting in persons with acquired brain injury. Behavioral Interventions, 20, 101-120.

Dixon, M.R., Marley, J., \& Jacobs, E.A. (2003). Delay discounting by pathological gamblers. Journal of Applied Behavior Analysis, 36, 449-458. 
Gray, J.R., Chabris, C.F., \& Braver, T.S. (2003). Neural mechanisms of general fluid intelligence. Nature Neuroscience, 6(3), 316-322.

Green, L., Fry, A.F., \& Myerson, J. (1994). Discounting of delayed rewards: A life-span comparison. Psychological Science, 5, 33-37.

Grossman, M. (1972). On the concept of health capital and the demand for health. Journal of Political Economy, 80(2), 223-255.

Hellige, J.B., \& Michimata, C. (1989). Categorization versus distance: Hemispheric differences for processing spatial information. Memory \& Cognition, 17, 770-776.

Jensen, A.R. (1998). The g factor: The science of mental ability. Westport, CT: Praeger.

Kirby, K. N., \& Marakovic, N. N. (1996). Delay-discounting probabilistic rewards: Rates decrease as amounts increase. Psychonomic Bulletin \& Review, 3(1), 100-104.

Kirby, K.N., Petry, N.M., \& Bickel, W.K. (1999). Heroin addicts have higher discount rates for delayed rewards than non-drug-using controls. Journal of Experimental Psychology: General, $128(1), 78-87$.

Laibson, D. (1997). Golden Eggs and Hyperbolic Discounting. Quarterly Journal of Economics. 62, pp. $443-77$.

Liebert, M.A., Chabris, C.F., Woolley, A.W., Gerbasi, M.E., Hackman, J.R., \& Kosslyn, S.M. (2007). Differences in cognitive abilities and information processing styles among occupational groups. Presented at the Academy of Management Conference, Philadelphia, PA, 9 August.

Loewenstein G., \& Prelec, D. (1992). Anomalies in Intertemporal Choice: Evidence and an Interpretation. The Quarterly Journal of Economics, 107(2), 573-597.

Mazur, J.E. (1987). An adjusting procedure for studying delayed reinforcement. In M.L. Commons, J.E. Mazur, J.A. Nevin, \& H. Rachlin (Eds.), Quantitative Analysis of Behavior: The Effects of Delay and Intervening Events on Reinforcement Value Vol. 5 (pp. 55-73). Hillsdale, NJ: Lawrence Earlbaum Associates. 
Mitchell, S.H. (1999). Measures of impulsivity in cigarette smokers and non-smokers. Psychopharmacology, 146, 455-464.

Myerson, J., \& Green, L. (1995). Discounting of delayed rewards: models of individual choice. Journal of the Experimental Analysis of Behavior, 64, 263-276.

Petry, N.M. (2001). Delay discounting of money and alcohol in actively using alcoholics, currently abstinent alcoholics, and controls. Psychopharmacology, 154, 243-250.

Rachlin, H., Raineri, A., \& Cross, D. (1991). Subjective probability and delay. Journal of the Experimental Analysis of Behavior, 55(2), 233-244.

Reynolds, B. (2006). A review of delay-discounting research with humans: Relations to drug use and gambling. Behavioural Pharmacology, 17, 651-667.

Richard, F.D., Bond Jr., C.F., \& Stokes-Zoota, J.J. (2003). One hundred years of social psychology quantitatively described. Review of General Psychology, 7, 331-363.

Ross, L., \& Nisbett, R.E. (1991). The person and the situation: Perspectives of social psychology. Philadelphia: Temple University Press.

Scharff, R.L., \& Viscusi, W.K. (in press). Heterogeneous rates of time preference and the decision to smoke. Economic Inquiry.

Shamosh, N.A., \& Gray, J.R. (2008). Delay discounting and intelligence: A meta-analysis. Intelligence, 36, 289-305.

Shepard, R.N., \& Metzler, J. (1971). Mental rotation of three-dimensional objects. Science, 171, 701-703.

Shephard, J.M., \& Kosslyn, S.M. (2005). The minicog rapid assessment battery: Developing a "blood pressure cuff for the mind." Aviation, Space, and Environmental Medicine, 76, 192-197.

Strotz, R. (1957). The Empirical Implications of a Utility Tree. Econometrica, 25(2), 269-280. 
Swann Jr., W.B., \& Selye, C. (2005). Personality psychology's comeback and its emerging symbiosis with social psychology. Personality and Social Psychology Bulletin, 31, 155-165.

Vandenberg, S.G., \& Kuse, A.R. (1978). Mental rotations, a group test of three-dimensional spatial visualization. Perceptual and Motor Skills, 47, 599-604. 


\section{Appendix 1a: Cognitive tests in Cognition study}

(1) A 12-item short form (constructed and validated by Bors \& Stokes, 1998) of Raven's Advanced Progressive Matrices (RAPM), the generally accepted best measure of general fluid intelligence (Jensen, 1998).

(2) A computerized version of the mental rotation test developed by Shepard and Metzler (1971), in which, on each of 80 trials, subjects must compare two images and decide whether they depict the same three-dimensional object.

(3) A six-minute 20-trial paper-and-pencil version of the same mental rotation task developed by Vandenberg and Kuse (1978).

(4) A 3-back working memory task developed by Gray et al. (2003) in which subjects view a series of words at a rate of approximately one every three seconds and must decide whether each one is identical to the one presented three earlier in the sequence, which totals 128 trials.

(5) A 144-trial version of the Multi-Source Interference Task (MSIT) developed by Bush et al. (2003), which is based on the classic Stroop inhibition test.

(6) A test of categorical spatial relations encoding in which subjects must decide on each trial whether a briefly-presented dot is above or below a horizontal bar.

(7) A test of coordinate spatial relations encoding, in which subjects see the same type of stimuli as in the previous task, but must decide whether the dot is inside or outside a distance of $8 \mathrm{~mm}$ from the bar. This task and the categorical task described above each included 96 trials and was based on similar tasks created by Hellige \& Michimata (1989).

(8) The Verbal Fluency test from the Dellis-Kaplan Executive Function System, which provides a measure of how many different words the participant can generate within certain specified categories in a fixed amount of time. Performance on each task was scored as the percentage of trials answered correctly, except for Verbal Fluency, which was scored as the total number of words generated across six one-minute trials. 


\section{Appendix 1b: Cognitive tests in Web study}

Tasks 1-9 are adapted from the MRAB (Shephard \& Kosslyn, 2005) and implemented in PsyScopeFL for online testing. Task 10 was designed specifically for this study, but is based on the first three trials of the Dellis-Kaplan verbal fluency task used in the Cognition Study.

(1) Vigilance: measures ability to maintain attention over time. (90 trials)

(2) Three-Term Reasoning: measures verbal problem-solving ability in resolving standard threeterm relational arguments. (8 trials)

(3) Divided Attention: measures ability to fixate simultaneously on two distinct stimuli or stimulus features. (40 trials)

(4) Mental Rotation: measures skill at spatial problem solving. (32 trials)

(5) Verbal Working Memory: measures ability to temporarily store and manipulate verbal information. (60 trials)

(6) Spatial Working Memory: measures capacity to temporarily store and manipulate spatial information. (60 trials)

(7) Filtering: measures capacity to focus on target information and ignore task-irrelevant information. (84 trials)

(8) Perceptual Reaction Time: measures speed of recognition and response to visual material. (40 trials)

(9) Cognitive Set-Switching: measures ability to sort stimuli according to specific criteria. (24 trials)

(10) Verbal Fluency: measures level of language skill and verbal processing. (3 trials)

\section{Appendix 2a: Health-related variables from the Weight study}

Exercise "Do you exercise regularly? Yes (1); No (0)" "About how many hours per week? 1-3 (3); 3-5; (2) 5+ (1)" "Overall intensity of workouts: Low (3); medium (2); high (1)"

Smoking "Do you smoke? Yes (1); No (0)?" "About how many packs do you smoke per week?"

Dieting "Are you currently following a specific diet plan? Yes (1); No (0)?" 


\section{Appendix 2b: Health-related variables from the Web study}

Exercise "How many hours per week are you physically active (for example, walking, working around the house, working out)?" "How many of those hours represent exercise primarily intended to improve or maintain your health or fitness?" "If you do any exercise primarily for health or fitness, how would you rate its intensity? Low (3); medium (2); high (1)"

Smoking "Do you smoke (including cigarettes, cigars, pipes, or anything else)? Yes (1); No (0)"

"If you smoke cigarettes, about how many packs do you smoke per week?"

Healthy food choices "In a typical week, how often do you choose your food (the type and/or amount) with health and fitness concerns in mind? Every meal (1); most meals (2); some meals (3); few meals (4); no meals (5)"

Dental check-ups "How often do you visit your dentist for a check-up? Two or more time a year (1); once per year (2); less than once per year (3); never (4)"

Prescription drug completion "When your doctor gives you a prescription to fill at the drugstore (excluding birth control), do you follow it exactly (for example, by going to the drugstore, picking up the medication, taking all of the medication on schedule, and finishing the entire prescription)? Always (1); usually (2); sometimes (3); rarely (4)"

Flossing "How often do you floss your teeth? At least once per day (1); Most days each week (2); Once or twice each week (3); Rarely or never (4)"

Overeating "In a typical week, how often do you eat more than you think you should eat? Every meal (5); most meals (4); some meals (3); few meals (2); no meals( 1 )"

\section{Appendix 2c: Finance-related variables from the Web study}

Late credit card payments "If you have any credit cards, over the past two years how many times were you charged a late fee for making a credit card payment after the deadline? Never (1) ; 1-2 times (2); 3-4 times (3); 5 or more times (4)"

Credit card bill "If you have any credit cards, over the past two years, how often have you paid your credit card bill in full, as opposed to paying less than the full amount? (Paying in full means 
carrying no debt to the next month's bill.) Never pay in full (5); rarely pay in full (4); pay in full about half of the time (3); usually pay in full (2); always pay in full (1)"

Percent saved "Over the past three years, what percentage of your income have you saved? (Please include savings into retirement plans and any other form of savings that you do.)"

Gambling "On average, how many days per month do you gamble money, including visiting casinos, buying lottery tickets, betting on sports, playing poker, etc? Never (1); sometimes but rarely (2); 2-5 days per month (3); 6-10 days per month (4); more than 10 days per month (5)"

Wealth accumulation (relative) "Compared to your friends who are close to you in age, how much wealth have you accumulated? (Wealth includes retirement savings, stocks, bonds, and mutual funds you own, money in bank accounts, the value of your home minus the mortgage, etc.) More than all of my friends (1); more than most (2); about average (3); less than most (4); less than all (5)" "Compared to the other members of your family in your generation-brothers, sisters, and cousins close to your age-how much wealth have you accumulated? More than all (1); more than most (2); about average (3); less than most (4); less than all (5)" 
Table 1: Time discounting trials

\begin{tabular}{llll}
\hline Order & SIR & LDR & Delay (days) \\
\hline 1 & $\$ 54$ & $\$ 55$ & 117 \\
2 & $\$ 55$ & $\$ 75$ & 61 \\
3 & $\$ 19$ & $\$ 25$ & 53 \\
4 & $\$ 31$ & $\$ 85$ & 7 \\
5 & $\$ 14$ & $\$ 25$ & 19 \\
6 & $\$ 47$ & $\$ 50$ & 160 \\
7 & $\$ 15$ & $\$ 35$ & 13 \\
8 & $\$ 25$ & $\$ 60$ & 14 \\
9 & $\$ 78$ & $\$ 80$ & 162 \\
10 & $\$ 40$ & $\$ 55$ & 62 \\
11 & $\$ 11$ & $\$ 30$ & 7 \\
12 & $\$ 67$ & $\$ 75$ & 119 \\
13 & $\$ 34$ & $\$ 35$ & 186 \\
14 & $\$ 27$ & $\$ 50$ & 21 \\
15 & $\$ 69$ & $\$ 85$ & 91 \\
16 & $\$ 49$ & $\$ 60$ & 89 \\
17 & $\$ 80$ & $\$ 85$ & 157 \\
18 & $\$ 24$ & $\$ 35$ & 29 \\
19 & $\$ 33$ & $\$ 80$ & 14 \\
20 & $\$ 28$ & $\$ 30$ & 179 \\
21 & $\$ 34$ & $\$ 50$ & 30 \\
22 & $\$ 25$ & $\$ 30$ & 80 \\
23 & $\$ 41$ & $\$ 75$ & 20 \\
24 & $\$ 54$ & $\$ 60$ & 111 \\
25 & $\$ 54$ & $\$ 80$ & 30 \\
26 & $\$ 22$ & $\$ 25$ & 136 \\
27 & $\$ 20$ & $\$ 55$ & 7 \\
\hline & & & \\
\hline
\end{tabular}


Table 2: Summary statistics

\begin{tabular}{lllllll}
\hline Study & Variable & Mean & Median & Std. Dev. & Min & Max \\
\hline Weight & Age & 30.4 & 27.0 & 10.3 & 18.0 & 59.0 \\
& Female & $50.8 \%$ & - & - & - & - \\
& Education & 15.1 & 16.0 & 2.5 & 12.0 & 22.0 \\
& BMI & 28.9 & 27.2 & 7.3 & 18.7 & 60.5 \\
\hline Cognition & Age & 26.1 & 22.0 & 10.1 & 18.0 & 60.0 \\
& Female & $52.4 \%$ & - & - & - & - \\
& Education & 14.2 & 12.0 & 2.7 & 12.0 & 22.0 \\
& BMI & 24.5 & 23.6 & 4.9 & 17.6 & 46.0 \\
\hline Web & Age & 31.4 & 28.0 & 9.0 & 18.0 & 61.0 \\
& Female & $66.9 \%$ & - & - & - & - \\
& Education & 18.5 & 18.0 & 2.9 & 13.0 & 34.0 \\
& BMI & 25.1 & 23.5 & 5.6 & 16.5 & 51.5 \\
\hline
\end{tabular}

Table 3: Regressions for Weight study; standard errors in parentheses; * significant at $10 \%$; ** significant at $5 \% ; * * *$ significant at $1 \%$

\begin{tabular}{llllllll}
\hline Indep Var & BMI & Smoking & $\begin{array}{l}\text { Smoking } \\
\text { (tobit) }\end{array}$ & Exercise & $\begin{array}{l}\text { Exercise } \\
\text { (tobit) }\end{array}$ & $\begin{array}{l}\text { Diet } \\
\text { (probit) }\end{array}$ \\
\hline Discounting & 87.552 & 11.531 & 11.599 & 14.089 & 28.321 & 2.607 & 11.229 \\
& $(30.723) * * *$ & $(5.183) * *$ & $(5.077)^{* *}$ & $(5.032)^{* * *}$ & $(9.364)^{* * *}$ & $(1.930)$ & $(7.485)$ \\
Age & 0.222 & 0.019 & 0.016 & -0.068 & -0.130 & -0.036 & -0.151 \\
& $(0.433)$ & $(0.073)$ & $(0.072)$ & $(0.071)$ & $(0.119)$ & $(0.027)$ & $(0.103)$ \\
Age $^{2} / 100$ & -0.086 & -0.012 & -0.008 & 0.090 & 0.180 & 0.050 & 0.216 \\
& $(0.600)$ & $(0.101)$ & $(0.099)$ & $(0.098)$ & $(0.166)$ & $(0.038)$ & $(0.148)$ \\
Female & 0.197 & -0.317 & -0.319 & 0.495 & 0.907 & -0.061 & -0.206 \\
& $(1.265)$ & $(0.213)$ & $(0.209)$ & $(0.207) * *$ & $(0.345)^{* * *}$ & $(0.079)$ & $(0.262)$ \\
BDI & 0.187 & 0.066 & 0.066 & 0.022 & 0.050 & 0.000 & 0.001 \\
& $(0.108) *$ & $(0.018) * * *$ & $(0.018) * * *$ & $(0.018)$ & $(0.030)^{*}$ & $(0.007)$ & $(0.022)$ \\
Education & -0.204 & -0.017 & -0.017 & -0.086 & -0.144 & -0.001 & 0.005 \\
& $(0.272)$ & $(0.046)$ & $(0.045)$ & $(0.045) *$ & $(0.073)^{*}$ & $(0.017)$ & $(0.056)$ \\
Observations & 126 & 126 & 126 & 126 & 126 & 126 & 126 \\
R-squared & 0.159 & 0.190 & 0.190 & 0.147 & 0.145 & 0.044 & 0.049 \\
\hline
\end{tabular}

Table 4: Summary of $R^{2}$ (Weight study)

\begin{tabular}{llllllll}
\hline & Combined & Discounting & Age, Age $^{2}$ & Age & Sex & BDI & Education \\
\hline BMI & 0.159 & 0.079 & 0.062 & 0.061 & 0.004 & 0.036 & 0.006 \\
Smoking & 0.190 & 0.059 & 0.014 & 0.014 & 0.035 & 0.117 & 0.016 \\
Exercise & 0.147 & 0.052 & 0.020 & 0.002 & 0.015 & 0.024 & 0.040 \\
Diet & 0.044 & 0.021 & 0.021 & 0.000 & 0.011 & 0.000 & 0.004 \\
\hline Average over behaviors & 0.135 & 0.053 & 0.029 & 0.019 & 0.016 & 0.044 & 0.017 \\
\hline
\end{tabular}


Table 5: Principal component coefficients (Weight study)

\begin{tabular}{lllll}
\hline Variable & Comp1 & Comp2 & Comp3 & Comp4 \\
\hline BMI & 0.430 & -0.635 & 0.442 & 0.466 \\
Smoking & 0.565 & 0.018 & -0.786 & 0.249 \\
Exercise & 0.628 & 0.028 & 0.216 & -0.747 \\
Diet & 0.318 & 0.772 & 0.374 & 0.404 \\
\hline
\end{tabular}

Table 6: Sum of standardized variables regressed on the discounting variable and other explanatory variables (Weight study)

\begin{tabular}{llllllll}
\hline & \multicolumn{5}{c}{ Index 1 } \\
\hline Discounting & 39.338 & 44.132 & & & & \\
Age & $(9.391)^{* * *}$ & $(9.601)^{* * *}$ & & & & \\
& -0.095 & & -0.180 & 0.032 & & \\
Age $^{2} / 100$ & $(0.132)$ & & $(0.140)$ & $(0.020)$ & & \\
& 0.171 & & 0.298 & & & & \\
Female & $(0.183)$ & & $(0.195)$ & & & & \\
& 0.050 & & & & -0.466 & & \\
BDI & $(0.387)$ & & & & $(0.419)$ & & \\
& 0.097 & & & & & 0.119 & \\
Education & $(0.033)^{* * *}$ & & & & & $(0.034)^{* * *}$ & \\
& -0.117 & & & & & & -0.188 \\
Observations & $(0.083)$ & & & & & & \\
R-squared & 126 & 126 & 126 & 126 & 126 & 126 & 126 \\
\hline
\end{tabular}

Table 7: First Principal component regressed on the discounting variable and other explanatory variables (Weight study)

\begin{tabular}{llllllll}
\hline \multicolumn{7}{c}{ Index 2 } \\
\hline Discounting & 19.845 & 21.993 & & & & \\
Age & $(4.744)^{* * *}$ & $(4.877)^{* * *}$ & & & & \\
& -0.041 & & -0.085 & 0.014 & & \\
Age $^{2} / 100$ & $(0.067)$ & & $(0.071)$ & $(0.010)$ & & \\
& 0.074 & & 0.140 & & & & \\
Female & $(0.093)$ & & $(0.099)$ & & & & \\
& 0.086 & & & & -0.179 & & \\
BDI & $(0.195)$ & & & & $(0.213)$ & & \\
& 0.053 & & & & & 0.064 & \\
Education & $(0.017)^{* * *}$ & & & & & $(0.017)^{* * *}$ & \\
& -0.067 & & & & & & -0.101 \\
Observations & $(0.042)$ & & & & & & \\
R-squared & 126 & 126 & 126 & 126 & 126 & 126 & 126 \\
\hline
\end{tabular}


Table 8: Regressions for Cognition study; standard errors in parentheses; * significant at $10 \%$; ** significant at 5\%; ${ }^{* *}$ significant at $1 \%$

\begin{tabular}{llll}
\hline & BMI & Exercise & $\begin{array}{l}\text { Exercise } \\
\text { (tobit) }\end{array}$ \\
\hline Discounting & 114.302 & 18.287 & 22.672 \\
& $(52.467)^{* *}$ & $(11.631)$ & $(14.042)$ \\
Age & -0.336 & -0.102 & -0.114 \\
& $(0.357)$ & $(0.079)$ & $(0.095)$ \\
Age $^{2} / 100$ & 0.004 & 0.001 & 0.001 \\
& $(0.005)$ & $(0.001)$ & $(0.001)$ \\
Female & -0.960 & 0.002 & 0.038 \\
& $(0.990)$ & $(0.220)$ & $(0.263)$ \\
Cognitive & -0.916 & 0.107 & 0.135 \\
& $(0.334)^{* * *}$ & $(0.074)$ & $(0.090)$ \\
Education & -0.218 & 0.103 & 0.115 \\
& $(0.261)$ & $(0.058)^{*}$ & $(0.069)$ \\
Observations & 103 & 103 & 103 \\
R-squared & 0.148 & 0.072 & 0.072 \\
\hline
\end{tabular}

Table 9: Summary of $R^{2}$ for Cognition study

\begin{tabular}{llllllll}
\hline & Combined & Discounting & Age, Age $^{2}$ & Age & Sex & Cognitive & Education \\
\hline BMI & 0.148 & 0.059 & 0.005 & 0.001 & 0.003 & 0.045 & 0.018 \\
Exercise Frequency & 0.072 & 0.012 & 0.004 & 0.000 & 0.000 & 0.017 & 0.008 \\
Average & 0.110 & 0.035 & 0.004 & 0.001 & 0.002 & 0.031 & 0.013 \\
\hline
\end{tabular}

Table 10: Sum of standardized health variables regressed on discounting and other explanatory variables (Cognition)

\begin{tabular}{llllllll}
\hline & \multicolumn{6}{c}{ Index } \\
\hline Discounting & 40.674 & 38.380 & & & & & \\
& $(14.658)^{* * *}$ & $(14.043)^{* * *}$ & & & & \\
Age & -0.166 & & -0.078 & -0.003 & & \\
& $(0.100)$ & & $(0.084)$ & $(0.013)$ & & & \\
Age $^{2} / 100$ & 0.002 & & 0.001 & & & & \\
& $(0.001)$ & & $(0.001)$ & & & & \\
Female & -0.193 & & & & -0.135 & & \\
& $(0.277)$ & & & & $(0.265)$ & & \\
Cognitive & -0.084 & & & & -0.050 & \\
& $(0.093)$ & & & & & $(0.080)$ & \\
Education & 0.054 & & & & & & -0.015 \\
& $(0.073)$ & & & & & & \\
Observations & 103 & 103 & 103 & 103 & 103 & 103 & 103 \\
R-squared & 0.099 & 0.069 & 0.009 & 0.001 & 0.003 & 0.004 & 0.001 \\
\hline
\end{tabular}


Table 11: Health behavior regressions (Web study)

\begin{tabular}{lllllllll}
\hline & BMI & Smoking & Exercise & Dentist & Overeat & Floss & Healthy Food & Follow Prescription \\
\hline Discounting & 94.321 & 2.907 & -46.477 & -1.553 & 1.698 & -2.481 & 3.583 & -8.332 \\
& $(31.704)^{* * *}$ & $(9.208)$ & $(33.828)$ & $(5.663)$ & $(5.455)$ & $(6.712)$ & $(5.519)$ & $(4.060)^{* *}$ \\
Age & 0.789 & 0.041 & -0.565 & 0.029 & 0.027 & 0.011 & 0.016 & 0.031 \\
& $(0.244)^{* * *}$ & $(0.071)$ & $(0.260)^{* *}$ & $(0.044)$ & $(0.042)$ & $(0.052)$ & $(0.042)$ & $(0.031)$ \\
Age $^{2} / 100$ & -0.884 & -0.028 & 0.731 & -0.063 & -0.036 & -0.028 & -0.028 & -0.047 \\
& $(0.324)^{* * *}$ & $(0.094)$ & $(0.346)^{* *}$ & $(0.058)$ & $(0.056)$ & $(0.069)$ & $(0.056)$ & $(0.042)$ \\
Female & -1.917 & 0.207 & 0.680 & -0.270 & -0.001 & -0.186 & -0.405 & 0.086 \\
& $(0.614)^{* * *}$ & $(0.178)$ & $(0.655)$ & $(0.110)^{* *}$ & $(0.106)$ & $(0.130)$ & $(0.107)^{* * *}$ & $(0.079)$ \\
Cognitive & -1.227 & -0.154 & 2.159 & 0.067 & -0.278 & -0.008 & 0.050 & -0.076 \\
& $(0.444)^{* * *}$ & $(0.129)$ & $(0.474)^{* * *}$ & $(0.079)$ & $(0.076)^{* * *}$ & $(0.094)$ & $(0.077)$ & $(0.057)$ \\
Education & -0.031 & -0.049 & 0.184 & 0.017 & 0.015 & 0.025 & -0.008 & -0.013 \\
& $(0.105)$ & $(0.031)$ & $(0.112)$ & $(0.019)$ & $(0.018)$ & $(0.022)$ & $(0.018)$ & $(0.013)$ \\
Observations & 326 & 326 & 326 & 326 & 326 & 326 & 326 & 326 \\
R-squared & 0.156 & 0.029 & 0.096 & 0.054 & 0.045 & 0.016 & 0.049 & 0.030 \\
\hline
\end{tabular}

Table 12: Financial behavior regressions (Web study)

\begin{tabular}{lllllll}
\hline & Gamble & Late fee & Bill payed in full & \% Saved & Wealth to friends & Wealth to siblings \\
\hline Discounting & 1.604 & 1.980 & 33.064 & 147.103 & 6.016 & -1.041 \\
& $(4.907)$ & $(4.833)$ & $(8.013)^{* * *}$ & $(115.762)$ & $(6.114)$ & $(6.704)$ \\
Age & 0.029 & 0.091 & 0.123 & 1.269 & 0.045 & -0.018 \\
& $(0.038)$ & $(0.037)^{* *}$ & $(0.062)^{* *}$ & $(0.891)$ & $(0.047)$ & $(0.052)$ \\
Age $^{2} / 100$ & -0.025 & -0.122 & -0.158 & -1.691 & -0.059 & 0.026 \\
& $(0.050)$ & $(0.049)^{* *}$ & $(0.082)^{*}$ & $(1.185)$ & $(0.063)$ & $(0.069)$ \\
Female & -0.218 & -0.032 & 0.341 & 4.289 & 0.094 & 0.000 \\
& $(0.095)^{* *}$ & $(0.094)$ & $(0.155)^{* *}$ & $(2.240)^{*}$ & $(0.118)$ & $(0.130)$ \\
Cognitive & -0.331 & -0.088 & -0.262 & -0.034 & 0.093 & -0.058 \\
& $(0.069)^{* * *}$ & $(0.068)$ & $(0.112)^{* *}$ & $(1.621)$ & $(0.086)$ & $(0.094)$ \\
Education & -0.015 & 0.025 & -0.010 & -0.015 & 0.016 & -0.025 \\
& $(0.016)$ & $(0.016)$ & $(0.027)$ & $(0.385)$ & $(0.020)$ & $(0.022)$ \\
Observations & 326 & 326 & 326 & 326 & 326 & 326 \\
R-squared & 0.115 & 0.037 & 0.091 & 0.023 & 0.016 & 0.007 \\
\hline
\end{tabular}


Table 13: Summary of $R^{2}$ (Web study)

\begin{tabular}{llllllll}
\hline & Combined & Discounting & Age,Age $^{2}$ & Age & Sex & Cognitve & Education \\
\hline BMI & 0.156 & 0.031 & 0.079 & 0.062 & 0.031 & 0.037 & 0.001 \\
Packs & 0.029 & 0.001 & 0.012 & 0.012 & 0.003 & 0.007 & 0.004 \\
Exercise frequency & 0.096 & 0.006 & 0.012 & 0.003 & 0.008 & 0.069 & 0.007 \\
Dentist & 0.054 & 0.001 & 0.032 & 0.028 & 0.016 & 0.003 & 0.001 \\
Eat more than you should & 0.045 & 0.000 & 0.004 & 0.002 & 0.001 & 0.040 & 0.002 \\
Floss & 0.016 & 0.001 & 0.005 & 0.004 & 0.006 & 0.000 & 0.003 \\
Healthy Food & 0.049 & 0.001 & 0.004 & 0.003 & 0.042 & 0.000 & 0.001 \\
Follow Prescription & 0.031 & 0.014 & 0.007 & 0.004 & 0.003 & 0.004 & 0.002 \\
Gamble & 0.115 & 0.001 & 0.021 & 0.020 & 0.024 & 0.086 & 0.002 \\
Credit card late fee & 0.037 & 0.000 & 0.025 & 0.002 & 0.001 & 0.005 & 0.012 \\
Credit card bill paid in full & 0.091 & 0.051 & 0.016 & 0.006 & 0.011 & 0.013 & 0.000 \\
Percent Saved & 0.023 & 0.005 & 0.007 & 0.000 & 0.012 & 0.000 & 0.000 \\
Wealth compared to friends & 0.016 & 0.003 & 0.005 & 0.001 & 0.003 & 0.005 & 0.004 \\
Wealth compared to siblings & 0.007 & 0.000 & 0.001 & 0.000 & 0.000 & 0.002 & 0.005 \\
\hline Average across behaviors & 0.055 & 0.008 & 0.016 & 0.011 & 0.011 & 0.019 & 0.003 \\
\hline
\end{tabular}

Table 14: Coefficients of First Principal Component (Web study)

\begin{tabular}{lc}
\hline Variable & First Principal Component \\
\hline BMI & 0.258 \\
Overeat & 0.205 \\
Healthy Food & 0.150 \\
Exercise & 0.017 \\
Dentist & 0.222 \\
Floss & 0.195 \\
Smoking & 0.160 \\
Savings & 0.311 \\
Late Fee & 0.281 \\
Gamble & 0.149 \\
Wealth (to friends) & 0.438 \\
Wealth (to siblings) & 0.423 \\
Bill Paid in Full & 0.417 \\
Prescription & 0.118 \\
\hline
\end{tabular}


Table 15: Index 1 regressions; sum of standardized behaviors (Web study)

\begin{tabular}{llllllll}
\hline & \multicolumn{5}{c}{ Index 1 } \\
\hline Discounting & 54.282 & 54.579 & & & & \\
& $(32.567)^{*}$ & $(32.451)^{*}$ & & & & \\
Age & 0.495 & & 0.512 & 0.041 & & \\
& $(0.251)^{* *}$ & & $(0.246)^{* *}$ & $(0.033)$ & & \\
Age $^{2} / 100$ & -0.637 & & -0.636 & & & & \\
& $(0.333)^{*}$ & & $(0.329)^{*}$ & & & & \\
Female & -0.718 & & & -0.822 & & \\
& $(0.630)$ & & & & $(0.630)$ & & \\
Cognitive & -0.796 & & & & -0.864 & \\
& $(0.456)^{*}$ & & & & & $(0.448)^{*}$ & \\
Education & 0.042 & & & & & & 0.069 \\
& $(0.108)$ & & & & & & \\
Observations & 326 & 326 & 326 & 326 & 326 & 326 & 326 \\
R-squared & 0.039 & 0.009 & 0.016 & 0.005 & 0.005 & 0.011 & 0.001 \\
\hline
\end{tabular}

Table 16: Index 2 regressions; first principal component of standardized behaviors (Web study)

\begin{tabular}{llllllll}
\hline & \multicolumn{5}{c}{ Index 2} \\
\hline Discounting & 19.026 & 19.184 & & & & \\
Age & $(9.504)^{* *}$ & $(9.483)^{* *}$ & & & & \\
& 0.171 & & 0.173 & 0.012 & & \\
Age $^{2} / 100$ & $(0.073)^{* *}$ & & $(0.072)^{* *}$ & $(0.010)$ & & \\
& -0.222 & & -0.218 & & & & \\
Female & $(0.097)^{* *}$ & & $(0.096)^{* *}$ & & & & \\
& -0.046 & & & -0.084 & & \\
Cognitive & $(0.184)$ & & & & $(0.185)$ & & \\
& -0.273 & & & & & -0.278 & \\
Education & $(0.133)^{* *}$ & & & & & $(0.131)^{* *}$ & \\
& 0.003 & & & & & & 0.012 \\
Observations & $(0.032)$ & & & & & & \\
R-squared & 326 & 326 & 326 & 326 & 326 & 326 & 326 \\
\hline
\end{tabular}

